\title{
Left Hemisphere Lateralization of Categorical Color Perception among Roman and Arabic Script Readers
}

\author{
Abdulrahman Al-Rasheed ${ }^{*}$, Anna Franklin², Gilda Drivonikou' ${ }^{2}$, Ian Davies ${ }^{2}$ \\ ${ }^{1}$ Department of Psychology, King Saud University, Riyadh, KSA \\ ${ }^{2}$ Department of Psychology, University of Surrey, Guilford, UK \\ Email: asalrasheed@ksu.edu.sa
}

Received 8 January 2014; revised 7 February 2014; accepted 4 March 2014

Copyright (C) 2014 by authors and Scientific Research Publishing Inc.

This work is licensed under the Creative Commons Attribution International License (CC BY). http://creativecommons.org/licenses/by/4.0/

(c) (i) Open Access

\section{Abstract}

So far, the Left Hemisphere (LH) bias in color Categorical Perception (CP) has been related to the linguistic nature of the LH and converging evidence to support this hypothesis has been presented in several studies. As, to date, no evidence of lateralized CP has been shown on right-to-left readers in support of this theory. However, the influence of reading habits to perception has been shown in various studies. This study aimed to investigate the possible effect of habitual scanning on lateralization of color $\mathrm{CP}$, by comparing participants from two languages who vary in their reading direction: right-to-left in Arabic and left-to-right in English. Lateralization of CP was then tested in two groups of Arabic and English. The Arabic group consisted of 35 undergraduate students at King Saud University. The English group consisted of 29 native English-speakers who were undergraduate students of Surrey University. Their ages range from 18 to 30 years. Two tasks were used to test this hypothesis: a visual search task with a reaction time measure; and a target detection task with eye-movement measure. Both samples performed similarly and the pattern of lateralization has been replicated, but this time, it has also been shown that the effect is independent of habitual reading direction. It appears that reading direction has no effect on how color $\mathrm{CP}$ is lateralized.

\section{Keywords}

Left Hemisphere; Lateralization; Categorical Perception; Linguistic; Reading Habits; Habitual Scanning; Reading Direction

\footnotetext{
${ }^{*}$ Corresponding author.
}

How to cite this paper: Al-Rasheed, A., Franklin, A., Drivonikou, G., \& Davies, I. (2014) Left Hemisphere Lateralization of Categorical Color Perception among Roman and Arabic Script Readers. Psychology, 5, 255-270. 


\section{Introduction}

The colour spectrum is a physical continuum but it is perceived discontinuously, as discrete categories or segments of hues (Harnad, 1987). This is part of an effect called Categorical Perception (henceforth, CP). CP is found when a continuum is divided into categories, and when these categories appear to affect discrimination. In operational terms, CP can be defined by faster and/or more accurate discrimination of pair of stimuli that cross a category boundary (across-category), than two stimuli from the same category (within-category), even when the stimulus differences between the pairs of stimuli are equal. This definition of CP will be used throughout, and is illustrated in the classic form shown in Figure 1.

Figure 1 shows four stimuli designated as B2, B1, G1 and G2. Two (B2, B1) belong to the same the linguistic category, blue, and two (G1, G2) belong to the linguistic category green, with the category boundary between B1 and G1. The separation between the adjacent stimuli is equal. Discrimination of the cross-category stimulus pair (B1, G1) is faster and/or more accurate than discrimination of the within-category stimuli, (B1, B2) or (G1, $\mathrm{G} 2)$.

CP was first shown in speech perception. Liberman, Harris, Hoffman and Griffith (1957) tested participants on an $\mathrm{X}-\mathrm{AB}$ task. The participant's task was to indicate whether stimulus $\mathrm{X}$ is the same as stimulus $\mathrm{A}$ or $\mathrm{B}$. The speech stimuli were from a continuum of sounds, varying in equal steps from one phoneme to another. Participants showed better discrimination when the target stimuli and test stimuli were from different phonemic categories than when they were from the same category. $\mathrm{CP}$ occurs for a range of perceptual phenomenon. For instance, perception of non speech sounds (e.g., Cutting \& Rosner, 1974; Pastore, Li \& Layer, 1990), perception of line length (Tajfel \& Wilkes, 1963), and also dimensions of face perception such as facial expressions (e.g., Etcoff \& Magee, 1992; Beale \& Keil, 1995; De Gelder, Teunisse, \& Benson, 1997; Campbell, Woll, Benson, \& Wallace, 1999; Bimler \& Kirkland, 2001; Campanella, Chrysochoos, \& Bruyer, 2001; Rossion, Shiltz, Laurence, Pirenne, \& Grommelinck, 2001; Levin \& Angelone, 2002).

Evidence for $\mathrm{CP}$ has also been reported on a wide range of colour perception tasks. For example, recognition memory and X-AB tasks (e.g., Uchikawa \& Shonida, 1996; Roberson, Davidoff, \& Braisby, 1999; Roberson \& Davidoff, 2000, Roberson Davies \& Davidoff, 2000; Pilling, Wiggett, Özgen, \& Davies, 2003) same-different tasks (e.g., Bornstein \& Korda, 1984; Boynton, Fargo, Olson, \& Smallman, 1989) similarity judgements (e.g., Laws, Davies, \& Andrews, 1995; Roberson, Davidoff, \& Braisby, 1999) and target detection and visual search tasks (e.g., Franklin, Pilling, \& Davies, 2005; Daoutis, Franklin, Riddett, Clifford, \& Davies, 2006a; Daoutis, Pilling, \& Davies, 2006b). In the 2-X-AB task, a target stimulus (e.g., blue1) is presented followed by two test stimuli; one of the test stimuli is identical to the target and the other one (the foil) is different. The foil can be either from same category as the target (e.g., blue2), or from a different category (e.g., green1). The task is to decide as fast as possible which of the test stimuli is identical to the target. The results showed that target identification was faster and/or more accurate for different category than same category foils. In the search task, a target stimulus is presented among other stimuli (distractors); the distractors can either be from the same category as the target (e.g., blue1 among blue2s) or from a different category to the target (blue1 among green1s). The task is to detect the location of the target as fast as possible. Detection of a target that is from a different category to the distractors is faster and/or more accurate than detection of a target from the same category as the distractors.

\subsection{Theories of $\mathrm{CP}$}

Although CP has been reported in a wide range of studies, it is not clear what the origin and nature of this effect is. The degree to which language and perception contribute to the category effect has been extensively debated. Three main ideas have been emerged from the literature to account for the origin and nature effect of the CP: CP is "hardwired" into the visual system—it is innate; CP is due to verbal labelling; CP is due to perceptual change.

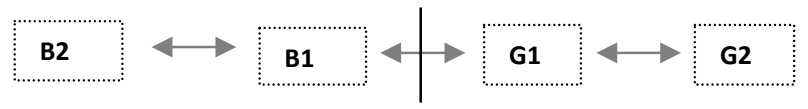

Figure 1. Diagram representing CP. There are four colours: two blues (B2, B1) and two greens (G1, G2). The arrows show the separation between adjacent pairs which are equally separated. The vertical line shows the category boundary. 


\subsubsection{Innate Perceptual Effect}

The principal claim of the Naturalistic theories (e.g., Bornstein, 1987; Snowden, 1987) is that, CP is an inborn, universal perceptual effect. Naturalistic theories are potentially supported by evidence for CP in young infants and in animals. Pre-linguistic participants perceive colour categorically before colour terms are learned. Bornstein, Kessen and Weiskopf, (1976) tested 4-month old infants for colour categorisation. Infants were habituated to a target coloured stimulus, then they were shown a test coloured stimulus. The test stimulus either belonged to a different category, or to the same category, as the target stimulus. Although physical distances between stimuli were equal, infants dishabituated to the novel stimulus only when the test stimulus belonged to a different category to the habituated stimulus. Franklin \& Davies (2004) also found evidence that infants had colour categories. Following familiarisation to one hue, infants only show novelty preference for a novel hue, if it comes from a different category to the familiarised hue. The findings are completely consistent with Bornstein et al.'s. Another study by Franklin, Pilling, \& Davies (2005) tested 4-to-6 month old infants for colour CP on a target detection task. Infants were shown a coloured target on a coloured background, with the target either from the same or different lexical category to the background. Infant eye movements to the target were recorded. Infants showed faster fixation of the target when the target and background were from different categories than from the same category. This findings provide strong evidence to support the naturalistic account of CP. Macaque monkey have also shown better discrimination for colours drawn from different categories than colours from the same category (Sandell, Gross, \& Bornstein, 1979). However, even if colour categories are found in pre-linguistic infants and in primates, colour categories need not necessarily be innate-even pre-linguistic colour categories could be learnt.

\subsubsection{Verbal Labelling}

Labelling theories argue that CP is driven by verbal labelling rather than by perception, and thus CP is not truly a perceptual phenomenon (e.g., Fujisaki \& Kwakshima, 1971; Kay \& Kempton, 1984; Roberson \& Davidoff, 2000). It is assumed that discrimination between perceptually different stimuli from different lexical categories is easier than stimuli from the same lexical category due to the different labels aiding discrimination. Thus, it is assumed that CP should not be shown when verbal labelling is absent. Evidence of the verbal account of the CP comes from cross-cultural and verbal interference studies. From the cross-cultural approach several studies (e.g., Kay \& Kempton, 1984; Roberson, Davies, \& Davidoff, 2000; Daoutis, Franklin, Riddett, Clifford, \& Davis, 2006a) report that CP only occurs when the categories boundaries are marked linguistically. Another set of studies investigated the contribution of verbal labelling to CP by adding verbal interference to the colour task (e.g., Roberson \& Davidoff, 2000; Pilling, Wiggett, Özgen, \& Davies, 2003; Winawer, Witthoft, Frank, Wu, Wade, \& Boroditsky, 2007). For instance, Roberson and Davidoff (2000) used a successive X-AB task. Participants were shown a target colour followed, after 5 seconds, by two test colours, the target and the foil. As described earlier, the foil was either from the same category as the target, or from a different category; the perceptual distance between the foil and the target was the same for both conditions. The participant's task was to decide which colour in the test pair was identical to the target. Three types of interference were used in the ISI period: visual interference, verbal interference and no interference. $\mathrm{CP}$ was found in the visual and no interference conditions, but not in the verbal interference condition. The elimination of CP by verbal interference was assumed to be due to the interference impeding the retention of the name (verbal label), thus forcing the task to be done using visual memory alone. As no CP now occurs, this was taken as evidence that the benefit of CP is due to comparison of verbal labels enhancing cross-category comparisons, but not enhancing within-category comparisons.

\subsubsection{Perceptual Change}

Perceptual change theories (e.g., Harnad, Hanson, \& Lubin, 1991; Goldstone, Lippa, \& Shiffrin, 2001) maintain that learning plays an important role in warping the representation of perceptual space. It is argued that learning to name a new stimulus dimension either in massed practice or in learning to distinguish the stimuli lexically leads to change in the representation of the stimulus dimension. Evidence from the perceptual learning experiment by Özgen and Davies (2002) has supported this idea. Participants were trained to learn a novel colour category such as yellowy-green vs. bluey-green. CP was then found around the recently learned category boundary. 


\subsection{Lateralisation of Colour CP to the Left Hemisphere (LH)}

To investigate further the contribution of language to CP, recent studies have considered how the effect is lateralised (e.g., Gilbert, Kay, Regier, \& Ivry, 2006; Drivonikou, Kay, Regier, Ivry, Franklin, \& Davies, 2007b; Roberson, Park, \& Hanley, 2008; Gilbert et al., 2006). Gilbert et al. reasoned that, as the left hemisphere is dominant for most language functions, if colour CP is related to language it should be stronger in the LH. To test this, Gilbert and colleagues used a visual search task where targets were lateralised to the left or right visual field (LVF/RVF). Stimuli were shown in a display of twelve coloured squares in a clock shape; eleven of the squares (the distractors) were identical in colour, and one (the target) was different. The relationship between the distractors and the target stimulus was manipulated so targets and distractors were either from the same colour category (e.g., blue 1 - blue 2 or green 1 - green 2), or from a different colour category (e.g., blue 1 - green 1 or green 1 - blue 1). While looking at a central fixation cross, participants had to decide whether the target was to the left or to the right of fixation. Gilbert et al. found that RTs were faster when target and distractors were different categorically (blue1 among green1s) than when target and distractors were just perceptually different (blue1 among blue2s). However, this category effect was found only if the target was presented to the RVF. Gilbert et al. argued that this pattern of lateralisation was consistent with CP being due to the implicit use of language.

As a further test of linguistic involvement in CP, Gilbert et al. used a version of the interference methods used by Roberson and Davidoff (2000) described earlier. In the verbal interference condition, a colour term was presented before the search display and had to be retained until after the response to the search display had been made. In the visual interference condition, a black and white chequer-board pattern presented before the search display had to be remembered until after the response to the search display. The trial started with fixation cross followed by either verbal or visual interference then the visual search display appeared. The LH category effect disappeared with verbal interference, but remained with visual interference.

The first replication of Gilbert et al. (2006) came from a re-analysis of a previous visual search study conducted by Daoutis, Pilling and Davies (2006b). They used a visual search task that required the detection of a target colour amongst two kinds of distractors. A target was only present on half of the trials and the task was to decide as quickly as possible if the target was present. Although on target present trials, half the time the target appeared in the LVF and half the time in the RVF, in the original paper, the possibility of visual field effects had not been considered. A reanalysis including visual field as a factor showed a stronger categorical effect for targets appearing in the RVF than for those appearing in the LVF. Drivonikou and colleagues then investigated whether lateralised CP would be found in a simplified version of Gilbert et al.'s search task, where there was a single target colour on a background of a different colour (see Franklin et al., 2005). Participants had to detect a circular coloured target that appeared in one of 12 locations on a coloured background. The target and background were from either just perceptually different (e.g., blue 1 among blue 2s) or physically and categorically different (e.g., blue1 among green1s) with the target-background perceptual distances equated across conditions. The results showed that RTs were faster when target and background were categorically different, than when they were just perceptually different. This category effect was found in both visual fields, but was larger in the RVF than LVF. In the same study, Drivonikou et al. also tested the blue-purple category boundary, and again, a category effect was found in the RVF, but not this time, in the LVF.

There is also evidence that LH lateralised colour CP only occurs if the category boundary is marked in the language. Korean has a lexical boundary between yeondu (yellow-green) and chorok (green) that is not marked in English. Roberson et al. (2008) compared English and Korean speakers using Gilbert et al.'s (2006) visual search task where the target-distractor relationship was either within-yeondu or -chorok, or between yeondu and chorok. CP was shown by Korean participants but not English participants, but there was no visual field by category interaction (the usual signature of lateralised CP). However, dividing the Korean group into fast and slow responders, using a median split, revealed that CP was lateralised to the RVF-LH for fast responders, but was present in both VFs for slow responders. Roberson et al. suggested that for slow responders, there was sufficient time for information to be transferred from the LH to the RH across the corpus callosum allowing language to influence performance in both visual fields.

Another cross-cultural study by Drivonikou, Davies, Franklin and Taylor (2007b) compared hemispheric asymmetry in colour CP for three samples: Greeks, English and "Africans". The same target detection task as in Drivonikou et al. (2007a) was used. Greek and English were tested for a category effect across two Greek basic 
colour categories ble "dark blue" and galazjo "light blue” which is not marked in English. A category effect was found for Greeks but not for English; moreover, for Greeks, the category effect was lateralised to the LH. The same task was used to test English and African participants for a category effect across the English blue-green boundary that is not marked in the various languages spoken by the African group. A category effect was found for the English group but not for the African group and for the English group, it was stronger in the LH than the RH.

Lateralisation of colour CP to the LH has been also been investigated using functional magnetic resonance imaging (fMRI: Siok, Kay, Wang, Chan, Chen, Luke, \& Tan, 2009) and the event-related potential (ERP) technique (Liu, Li, Campos, Wang, Zhang, Qiu, Zhang, \& Sun, 2009). In Siok et al. Chinese participants' brain activity was scanned while they performed a visual search task. The task, procedure and design were the same as Gilbert et al.'s. (2006). There was stronger activity in the language regions of the brain (the posterior temporoparietal area, the middle temporal gyrus and the inferior prefrontal cortex) in the left cerebral hemisphere for across-than for within-category discriminations in the RVF. This was also associated with greater activation in visual cortex for across-than for within-category discriminations. Liu et al. (2009) tested 12 adult Chinese on the same visual search task. N2pc (N2-posterior-contralateral) was used as an index of the attentionional demands of within- and across-category target-distractor relationships in the visual search task. The N2pc components in the LH were larger for the cross-category condition than for the within category conditions.

\subsection{Hemispheric Asymmetries in Colour CP in Pre-Linguistic Infants}

As discussed earlier, 4 - 6 month old infants also respond categorically to colour (Bornstein et al., 1976; Franklin \& Davies, 2004). Lateralisation of the category effect in infancy was tested by Franklin, Drivonikou, Bevis, Davies, Kay and Regier (2008). If the LH category effect is due to language, as the previous studies suggest, then there should be no LH bias for the category effect in infants. To investigate this, infants' and adults' eye movements were recorded on a target detection task, with across- and within-category conditions. Although the chromatic difference between the stimulus pairs (across- and within-pairs) was the same, both samples were faster at initiating an eye movement to the target on a background from a different category than a background from the same category. For adults, the category effect was stronger for the RVF than for the LVF. In contrast, for infants the category effect was only found for targets presented to the LVF. Therefore, it appears from this study that pre-linguistic CP is actually lateralised to the $R H$.

Franklin, Drivonikou, Clifford, Kay, Regier and Davies (2008) then investigated whether the lateralisation of colour CP switches from LH to RH as colour terms are learned. Two to five year old toddlers were tested on the same task as the study of lateralised colour CP in infants. The participants were divided into two groups. One group had knowledge of the terms for the colours used in the study, and the other group was still learning these terms. Toddler's eye movement initiation times to the target were measured. Both groups showed a category effect, but the pattern of lateralisation was different for the two groups. For the group who knew the words for the blue and green, CP was found in the RVF (LH) - the same pattern as found in adult studies described above. For toddlers who did not know the words for blue and green, the CP effect was found only in the LVF (RH). It was concluded that the acquisition of colour terms was related to the RH-LH switch in colour CP.

\subsection{Lateralisation of Categorical Processing beyond Colour}

Gilbert, Regier, Kay, \& Ivry, (2007) also investigated whether LH lateralisation of category effects in adults extended beyond the colour domain. They used their original visual search task but instead of colour, the stimuli used were drawings of cats or dogs. The key comparison was, as usual, whether the target-distractor relationship was within-category (e.g., cat1-cat2) or between-category (e.g., cat1-dog1). The results showed that the crosscategory targets were detected more quickly than the within-category targets in both visual fields, but the effect was stronger in the RVF (LH) than in the LVF (RH).

There are also examples of LH category effects in adults for types of categorical responding other than CP. For example, Kosslyn, Koenig, Barrett, Cave, Tang, \& Gabrieli (1989) reported a series of experiments that explored the contribution of the left and right hemispheres to computing categorical and metric spatial judgments. The results of these experiments indicated that categorical judgments (such as on/off, left/right, and above/below) are faster for RVF (LH) stimuli, whilst metric judgments, such as the evaluation of absolute distance (is it $2 \mathrm{~mm}$, $3 \mathrm{~mm}, 2.54 \mathrm{~cm}$ ), are faster for LVF (RH) stimuli. This difference in hemispheric processing modes has been 
supported by a large body of subsequent research (see Jager \& Postma, 2003 for a review).

\subsection{Potential Influences on the Lateralisation of CP}

So far, the LH bias in colour CP has been related to the linguistic nature of the LH and converging evidence to support this hypothesis has been presented. However, it is also possible that other factors contribute the LH bias in category effect in adults. The first two experiments in this chapter explore whether the LH bias in category effect could be, in part, due to an attentional bias arising from the habitual left to right scanning pattern occurring in reading for those using Roman script.

Eviatar (1995 and 1997), compared left-to-right and right-to-left (Hebrew readers) using a target detection task. Targets occurred in one visual field together with irrelevant distractors in the other field. Left-to-right readers were impaired by LVF distractors, but not by RVF distractors. Hebrew-readers showed the opposite pattern: they were impaired by RVF but not by LVF distractors. Eviatar suggested that the habitual reading direction resulted in attentional priority being given to the LVF for left-to-right readers and to the RVF in right-toleft readers. The effect was "automatic" and could not easily be "turned off" even when it impaired performance.

Applying this to Gilbert et al.'s search task, detecting a LVF target should not be impaired by the simultaneous presence of RVF distractors. In contrast, detection of RVF targets should be impaired by LVF targets. If this holds, then there should be an overall visual field effect with LVF detections being better than RVF detections. However, Gilbert et al.'s crucial result, is not about overall visual field effects; rather, the crucial result is that detecting RVF (LH) targets is better than for $\mathrm{LVF}(\mathrm{RH})$ targets, but only for across-category target-distractor displays. Without additional ad hoc assumptions, it is not clear how Eviatar's hypothesis could lead to the crucial field by category interaction. Nevertheless, it is possible that right-to left readers would not be inhibited by LVF distractors, and could show stronger RVF detection than left-to-right readers.

There is a second effect related to reading direction that could also benefit RVF detection over LVF target detection. Simola, Holmqvist and Lindgren (2009) found that right-to-left readers benefited from parafoveal information to the right of fixation, while left-to-right viewers, benefited from parafoveal information to the left of fixation. Applying this to the search and target detection tasks, suggests that as observer's are fixating the centre of the display, target detection should be better in one visual field than the other; and the direction of the effect should depend on habitual reading direction.

As earlier, it is not clear how the field biases just described could produce the pattern of lateralisation found by Gilbert et al and Drivonikou et al. However, it does suggest that there could be overall differences in visual field biases related to habitual reading direction.

Although it is not entirely clear how to predict the effect of habitual reading direction on target detection tasks, I decided that it was worth exploring to test the generality of laterality effects across cultures and reading directions. Han and Northoff (2008) describe several instances of cultural differences being associated with differing neural organisations, and argue that in general, it is good practice to test the generality of findings across a range of cultures. Their exhortation is consonant with the motivation behind this chapter, which is to test that patterns of lateralisation are independent of seemingly small scale procedural task variations, as well as generalising across culture and reading direction.

As, to date, no studies of lateralised CP have been conducted on right-to-left readers and as there are some 500 million of them (Kazandjian \& Chokron, 2008), the next two experiments report comparisons of readers of Arabic and readers of English using the target detection task.

\subsection{Aim of the Study}

The aim of the current paper is to investigate whether the lateralisation of colour CP is affected by reading direction. All of the studies that have tested the LH lateralised of colour CP in adults (e.g., Gilbert et al., 2006; Drivonikou et al., 2007a \& b; Roberson et al., 2008; Tan, Chan, Kay, Khong, Yip, \& Luke, 2008; Liu et al., 2009) have examined the lateralisation of colour CP with left-to-right script readers. However, the influence of reading habits to perception has been shown in several studies (e.g., Eviatar, 1995, 1997; Farid \& Grainger, 1996; Prunet, Beland, \& Adrissi, 2000; Berent, 2002; Schwalm, Eviatar, Golan, \& Blumenfeld, 2003). This study investigates the possible effect of habitual scanning on lateralisation of colour CP, by comparing participants from two languages who vary in their reading direction: left-to-right in English and right-to-left in Arabic. A preliminary study (Al-rasheed, 2010) established the location of the azrock "blue"- akhdar, "green" boundary 
in Arabic. As the boundary was at more or less the same location as in English, Lateralisation of CP was then tested in the two groups using first, a visual search task, (Experiment 1) and then a target detection task with eye-movement latencies as the dependent variable (Experiment 2).

\section{Experiment 1: Hemispheric Asymmetries in Visual Search Task}

\subsection{Introduction}

Gilbert et al. (2006) used a lateralised visual search task to investigate the lateralisation of colour CP. The results of Gilbert et al. and other studies (Daoutis et al, 2006b; Drivonikou et al, 2007a; Roberson et al, 2008; Tan et al, 2008; Liu, 2009) showed that left-to-right script readers discriminated pairs of stimuli from different colour categories faster than same-category pairs, even though the separation of within- and between-category pairs of were equal. Crucially, however, this categorical effect is strongest for RVF (LH) targets.

Experiment 1 was carried out to investigate whether habitual reading direction might affect the pattern of lateralisation. Arabic speakers, who read from right-to-left, and English speakers who read from left-to-right, were tested. CP was investigated using a version of the search task originally used by Gilbert et al., described earlier.

\subsection{Method}

\subsubsection{Participants}

There were two groups of subjects: “English” and “Arabic”. The English group consisted of eleven native English-speakers who were undergraduate students or staff at University of Surrey. Their ages ranged from 18 to 40 years with a mean of $25.6(\mathrm{SD}=8)$. The Arabic group consisted of 15 undergraduate students at King Saud University, with ages ranging from 19 to 23 years with a mean of $20.4(\mathrm{SD}=1)$. All participated for course credits, or were paid for their participation. Based on self-report, all the participants were right-handed and had normal colour vision, as indicated by the City University Test (Fletcher, 1980) for the English speakers and by Ishihara's Test for Colour-Blindness (Ishihara, 1987) for the Arabic participants.

\subsubsection{Stimuli}

As shown in Figure 2, three stimuli were used so that two of them fell into the blue category and the other fell into the green category. The Munsell hues were 5BG, 10BG and 5B. The value and chroma were constant at (6/7), and the separation was 5 hue steps $(\Delta \mathrm{E} \sim 15)$. Their CIELUV coordinates $\left(\mathrm{u}^{*} \mathrm{v}^{*}\right)$ were $-45.65,-2.73$; $-44.83-18.68$; and $-39.62-32.97$; all at $\mathrm{L}^{*}=61.70$. The $\mathrm{Y} x$ y coordinates for the grey background and the white point of the monitor were: 19.47, 0.336, 0.344; 64.80. 0.326. 0.335.

The blue-green boundary for both samples was (7.5BG). Adjacent stimuli were paired, giving one withincategory pair (B1-B2) and one between category pair. The target for all trials was blue1 and the 11 distractors were randomly switched between within-category (blue2) and across-category (green1). The stimuli were displayed on a 17-inch CRT; a Cambridge Research Instruments ColorCAL was used to obtain the CIE co-coordinates.

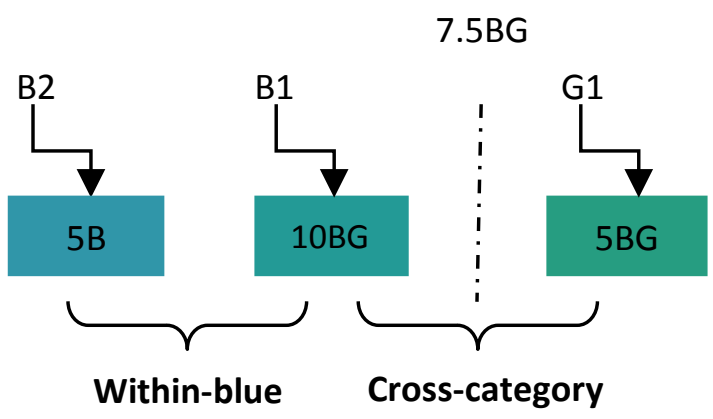

Figure 2. Illustration of the Munsell codes of the three stimuli used. Stimuli B2 and B1 are from the same category, while stimulus G1 belongs to a different category. Stimuli B2, B1 and G1 are equally separated. The line between B1 and G1 indicates the English and Arabic blue-green boundary. 


\subsubsection{Procedure}

There were twelve circular stimuli displayed in a clock shape (30 mm diameter, $\sim 3.5^{\circ}$ viewed from $500 \mathrm{~mm}$ ) with six set on the right of central fixation cross and the other six on the left. One stimulus, the "target", varied in hue from the rest (11 distractors) appeared randomly in one of the 12 equally separated $\left(30^{\circ}\right)$ locations on a notional circle of $110 \mathrm{~mm}$ diameter around the fixation cross at the centre of the monitor. The stimuli were displayed against a grey background on each trial. An example of the task was shown in Figure 3.

The experiment began with a fixation cross which remained for $100 \mathrm{~ms}$ to alert the participants that the trial was beginning. Then the stimulus followed and remained on screen for $200 \mathrm{~ms}$. The next trial began when the participants had responded. There were 192 trials made up from 48 trials of each combination of visual field (left or right of fixation) and within- and across-category. There were also 10 practice trials before starting the experiment proper, and they took about ten minutes to complete the task.

The participants were tested individually in a dark room, and were seated $60 \mathrm{~cm}$ away from the monitor and at eye-level to the centre of the monitor, with head restrained using a chin rest. Participants were instructed to click on the right mouse button as quickly as possible when the target appeared in one of the six locations set on the right of central fixation, and click on the left mouse button as quickly as possible when the target appeared in one of the six locations set on the left of central fixation. They were also told that on each trial the target could appear in any one of the twelve locations at random.

\subsection{Results}

The percentage of incorrect trials for each combination of category (within/cross), visual field (left/right) and language (English or Arabic) were calculated for each subject. A three-way ANOVA (Category by Visual Field by Language), with repeated measures on the first two factors, showed that the only significant effect was for Category (all other Fs $<1$ ). Cross-category errors rate (mean $=2.93 \%$, $\mathrm{SD}=3.51$ ) were about $1 \%$ lower than within-category responses (mean $=4.02, \mathrm{SD}=4.98), F(1,24)=0.27, M S E=30.55, p<0.05$.

Median response times (RTs) for each subject were calculated for each combination of visual field and category for correct trials. Although English speakers (mean $=437 \mathrm{~ms}, \mathrm{SD}=60$ ) responded $\sim 25 \mathrm{~ms}$ faster than Arabic speakers (mean $=465, \mathrm{SD}=85$ ), this difference was not significant $(F(1,24)=0.90, M S E=19732.82, p$ $=0.35$ ). Nor did the language factor interact with any of the other factors: (largest $F=0.94$, smallest $p=0.34$ ). Cross-category responses (mean $=442.81, \mathrm{SD}=75.87$ ) were about $20 \mathrm{~ms}$ faster than within-category responses $($ mean $=463.32, \mathrm{SD}=75.62 ; F(1,24)=9.84, M S E=10481.84, p<0.005)$. There was also a significant effect of visual field $(F(1,24)=6.94, \mathrm{MSE}=2000.12, p<0.05)$ with the RVF responses (mean $=446.48, \mathrm{SD}=78.86$ ) being about $9 \mathrm{~ms}$ faster than LVF responses (mean $=455.36$, $\mathrm{SD}=73.71$ ). The category effect was about $15 \mathrm{~ms}$ larger in the RVF than in the LVF. The Category by Visual Field interaction was also significant, $F(1.24)=6.42$, MSE $=1378.42, p<0.005$. From Figure 4 the interaction appears to be due to the larger category effect in the RVF ( $25 \mathrm{~ms})$ compared to the LVF ( 10 ms).

This impression was supported by paired samples $t$-tests (2-tailed) used to investigate the interaction. There was a significant category effect for the RVF $(t(25)=3.98, p<0.001)$, but not for the LVF $(t(25)=1.96, p=$ 0.062). Moreover, for cross-category trials, RVF responses were faster than LVF responses $(t(25)=3.42, p<$ 0.005 ) but there was no effect of visual field for within-category responses $(t(25)=0.28, p=0.78)$.

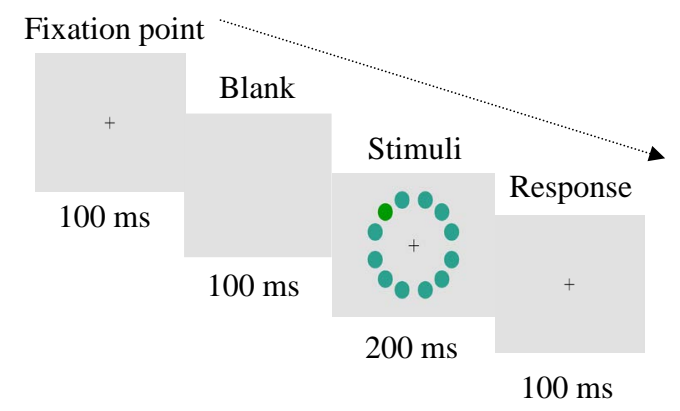

Figure 3. Sample of the visual search task, the green dot shows the target, and the other 11 circles indicate the distractors. 


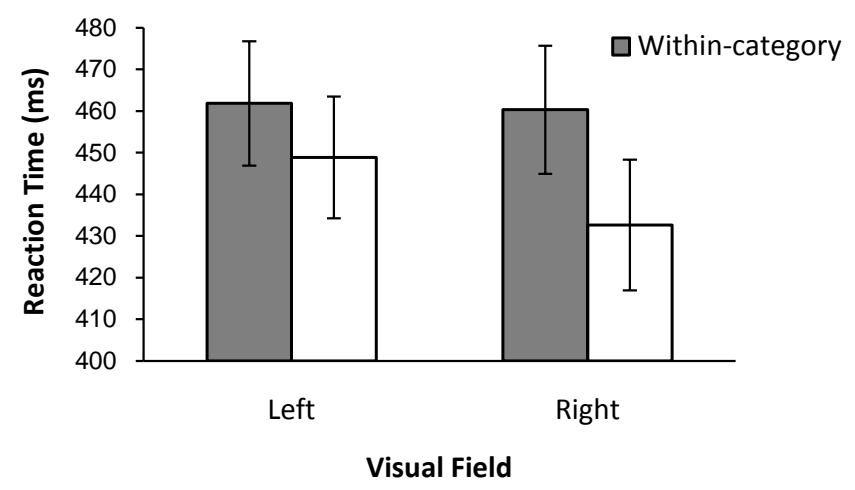

Figure 4. Mean response times (+/-1se) with standard error bars for correct trials for Arabic and English speakers for identification of the left/right location of chromatic target among distractors from either a different or same category.

\subsection{Discussion}

Discrimination of target and distractors was faster when they were categorically different than when they were just perceptually different. However, this category effect was stronger for RVF targets than LVF targets thus replicating Gilbert et al. (2006). Crucially, there was no suggestion that this pattern differed between the two groups with different habitual reading directions.

\section{Experiment 2: Hemispheric Asymmetries on a Target Detection Task with an Eye-Movement Measure}

\subsection{Introduction}

Experiment 2 used a version of Gilbert et al.'s visual search task to investigate the lateralisation of colour CP to the LH in two samples varying in their scanning habit testing Arabic (right-to-left) and English (left-to-right). The result of this experiment replicated the findings of Gilbert et al. and Drivonikou et al. A hemispheric asymmetry in CP was shown with a significant CP effect for RVF but not LVF targets. The current experiment checks whether the LH bias in colour CP for Arabic speakers is also found when using an eye-movement measure. Franklin et al. (2008a) measured the time to initiate an eye-movement to the target in their study of lateralised colour CP in infants. In the current study, the same eye-movement measure was used with readers of a right-to-left script to test whether habitual scanning direction could influence the LH category effect. If so, then the Arabic participants, who have right-left reading and writing habits, could show a different pattern than that shown by the English Adults reading left-to-right Roman script in the Franklin et al. (2007) study.

\subsection{Method}

\subsubsection{Participants}

There were two groups of subjects, "English” and “Arabic” all from the University of Surrey. Based on self-report, all were right-handed and reported normal colour vision, as indicated by the City University Test (Fletcher, 1980). Twenty of them were native Arabic speakers, 8 females and 12 males aged between 18 and 30 years old with a mean age of 27.05 years ( $S D=4.50$ ). None had lived in the UK for more than two years, and none of them had taken part in the previous study. Eighteen were native speakers of English, 11 females and 7 males, aged between 18 and 30 years old with a mean age of 21.83 years $(\mathrm{SD}=3.85)$.

\subsubsection{Apparatus and Experimental Set Up}

The apparatus was the same as in the previous experiment with the addition of an ASL 504 pan/tilt eye-tracking camera mounted directly below the monitor. This camera is sensitive to near-infrared light, enabling a participant's eye movements to be recorded in the dark. An analogue digital video converter (Canopus ADVALUE AND CHROMA-300) digitised the eye-movement output and I-movie 2.1.2 software analysed the digital video. 


\subsubsection{Stimuli}

As shown in Figure 5, three stimuli were used varying only in Munsell Hue with Value and Chroma constant at 6/8. The separation between adjacent stimuli was 2.5 Munsell hue steps $(\Delta \mathrm{E} \sim 9)$. Two stimuli were green (3.75BG and 6.25BG) and the third was blue (8.75BG). The CIE (1931) Y, x, y chromaticity coordinates of the colours and of the grey and white point of the monitor were: 19.47, 0.228, 0.342; 19.47, 0.220, 0.322; 19.47, 0.214, 0.304; 19.47, 0.336, 0.344; 64.80. 0.326. 0.335 .

\subsubsection{Procedure}

Adjacent stimuli were paired, to give one within-category pair (green 1 - green 2) and one between-category pair (green1-blue1). For each pair, on a given trial, one stimulus was used as the target and one stimulus as the background. However, across trials, each stimulus within a pair was used as the target half of the time and half of the time as the background.

A circular target $\left(3 \mathrm{~cm}\right.$ diameter, visual angle $\left.=3.22^{\circ}\right)$ appeared on a coloured background $(40 \times 30 \mathrm{~cm})$ at one of twelve locations arranged radially around a central point, half of them located in the left visual field (right hemisphere) and half in the right visual field (left hemisphere) with a fixation cross in the centre (Figure 6).

Participants were seated in front of the monitor, and were instructed to keep their eyes on the centre of the screen and to hold their head up and in a stable position throughout the calibration and experimental phases. The pan/tilt eye-tracking camera was angled by a remote control to capture the participant's eye, so that the eye was put into focus, and the crosshairs for the pupil signal and corneal reflection were found and appeared on the image of the eye on the video monitor.

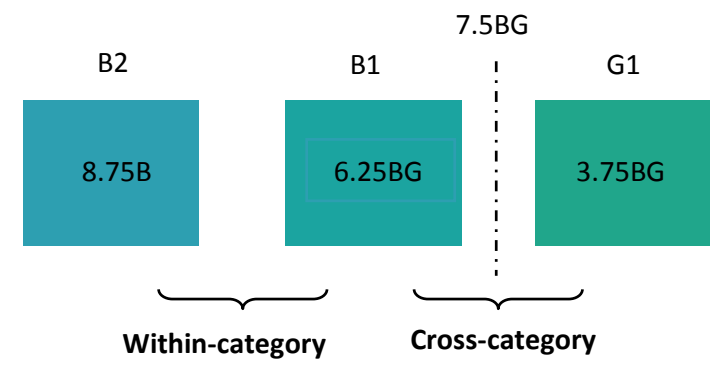

Figure 5. Illustration of the Munsell codes of the three stimuli used. Stimuli B2 and B1 are from the same category, while stimulus G1 belongs to a different category. Adjacent pairs were separated by 2.5 Hue steps. The line between B1 and G1 indicates the English and Arabic blue-green boundary.

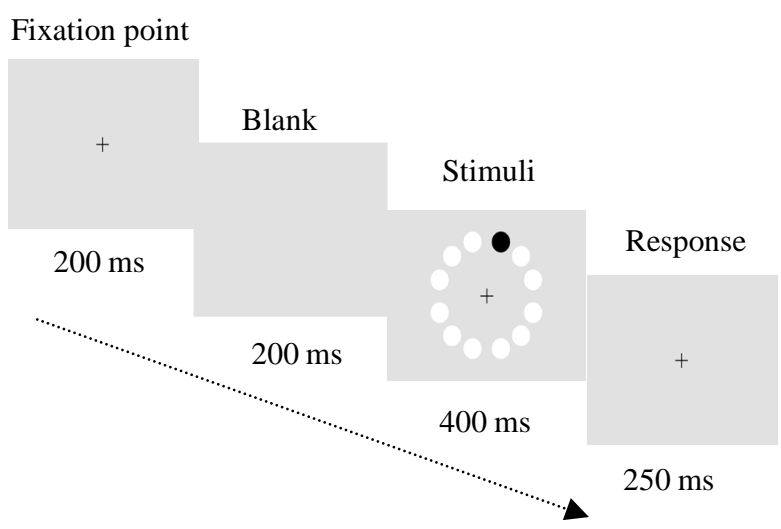

Figure 6. Example of the target detection task, the black dot shows the target, and the other 11 white circles indicate the possible target locations. 
The calibration procedure (see Franklin, Pilling, \& Davies, 2005) preceded the main data collection phase. Nine numbers displayed in a grid shape appeared on the CRT, and the participant was asked to look at the nine numbers as requested by the experimenter. The nine points were given to each participant in a different order, after all nine points had been hit by the corneal reflection and pupil signal crosshair, the calibration phase was accurate and achieved. The calibration procedure was repeated when the crosshair failed to hit one of the nine points.

After calibration, the main data collection phase started. To ensure central fixation, each trial began with a black and white looming and expanding "attention-getter" on a grey background. Following fixation, a blank grey background of the same luminance as the target appeared for $250 \mathrm{~ms}$, followed by a 4-second presentation of the target and background. The target location was randomised across trials, with the constraint that it appeared to the left and right of fixation equally often. The experiment was run in two blocks, each consisting of 16 trials.

\subsection{Results}

Initiation time data were derived using point of gaze (POG) coordinates and the videotaped output. The initiation time was calculated as the time from onset of the target until the start of an eye-movement to the target. Trials were excluded from the analysis for two reasons: when the eye-movement signal was lost (Arabic: mean = 3.4, SD 6.8; English mean $=2.39$, SD 3.16); when multiple eye-movements were made before the eye movement to the target (Arabic mean $=6.9$, SD 5.3; English mean $=5.11$, SD 3.5). The average number of trials analysed was 48.95 for Arabic and 56.5 for English. There were at least 10 trials analysed for each participant in both samples.

As the language factor did not interact whit any other factor, shows the mean initiation time (ms) across participants for correct trials for each combination of visual field (left or right) and category (within-across) collapsed across the language factor. Three way mixed ANOVA was performed on the initiation time data for the three factors: (Category: cross-category within-category), (Visual Field: Left Right) and (Language: Arabic English).

The Arabic group (mean $=357.25 \mathrm{~ms}, \mathrm{SD}=74$ ) initiated eye movements about $30 \mathrm{~ms}$ faster than the English group (mean $=391.95 \mathrm{~ms}, \mathrm{SD}=82 ; F(1,36)=5.06, M S E=45614.06, p<0.05)$. There was also a very strong category effect $(F(1,36)=248.34, M S E=400076.05, p<0.001)$. Initiation time was about $100 \mathrm{~ms}$ faster for the cross-category condition (mean $=323.59 \mathrm{~ms}, \mathrm{SD}=51.59$ ) than the within-category condition (mean $=420.76$ $\mathrm{ms}, \mathrm{SD}=73.76$ ). The effect of Visual Field was not significant, but there was trend for initiation time to be faster for the RVF condition (mean $=367.30 \mathrm{~ms}, \mathrm{SD}=75.45$ ) than the LVF condition (mean $=377.05 \mathrm{~ms}, \mathrm{SD}=$ 84.53; $F(1,36)=3.47, M S E=5842.37, p=0.071)$. Crucially, the interaction between Category and Visual Field was also significant $(F(1,36)=7.86, p<0.005)$ and this interaction is explored below. There was no significant interaction of Language with the other factors, however, the Language by Category interaction approached significance $(F(1,36)=3.53, M S E=5686.57, p=0.068$; for the remaining interactions, largest $F=0.38)$.

From Figure 7 there appear to be two reasons for the category by field interaction. First, the size of the category effect is larger in the RVF (11 ms) than in the LFV (88 ms). And second, the within-category condition appears to be faster in the LVF than in the RVF by about $25 \mathrm{~ms}$, whereas there seems to be no effect of visual field on the between category condition. A series of post hoc paired sample $t$-tests supported these impressions. While the category effect was present in both visual fields (RVF, $t(37), 13.99, p<0.001$; LVF $t(37), 9.89, p<$ $0.001)$ the effect was larger in the RVF than in the LVF $(t(37), 2.86, p<0.05)$. Comparing visual fields, confirmed that for within-category conditions, the LVF was faster than for the RVF $(t(37), 2.73, p<0.01)$ whereas there was no field effect for between category conditions ( $t(37), 0.42, p=0.68)$.

\subsection{Discussion}

For both Arabic and English participants, discrimination of pairs of colours from different lexical categories (blue and green) was faster than pairs from the same lexical categories (different shades of blue). While, this categorical effect was present in both visual fields, it was stronger in the RFV than in the LVF. Yet again, the pattern of lateralisation first reported by Gilbert et al. (2006) has been replicated, but this time, it has also been shown that the effect is independent of habitual reading direction. All of the research on lateralisation of colour CP before this study was conducted with participants reading left-to-right Roman script (Gilbert et al, 2006; 


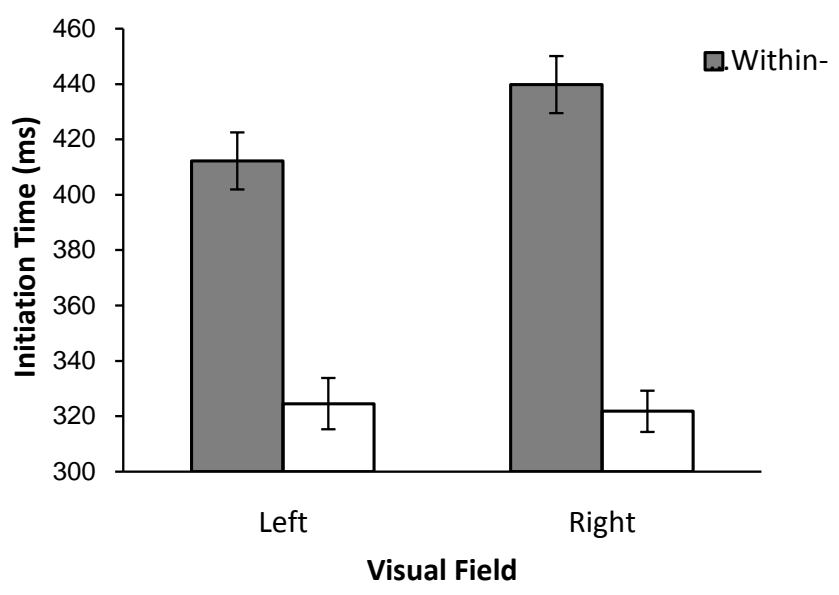

Figure 7. Mean response times (+/-1se) with standard error bars for correct trials for Arabic and English speakers for identification of the left/right location of chromatic target among distractors from either a different or same category.

Drivonnikou et al, 2007a \& b; Roberson, 2008; Franklin et al. 2008a \& b). In this experiment, we show that as in Experiment 1, but this time using an eye-movement measure, that readers of right-to-left scripts, such as Arabic, show essentially the same pattern as the current English sample, and the adult English sample in Franklin et al. (2007). It appears that reading direction has no effect on how colour CP is lateralised.

\section{General Discussion}

The overall aim of the experiments presented in this paper was to assess whether previous findings of LH lateralised colour $\mathrm{CP}$ are independent of reading direction, the number of distractors and the nature of the target-decision. In brief, the "robustness" of the effect. The previous studies that found LH colour CP (e.g., Gilbert et al., 2006; Drivonikou et al., 2007a \& b; Franklin et al., 2007; Roberson et al., 2008 and 2008; Siok et al., 2009; Liu et al., 2009) have all tested participants who read left-to-right scripts (or top to bottom scripts), but participants who read from right-to-left had not been tested. Reading direction affects the pattern of lateralisation on a range of perceptual tasks (Eviatar, 1995, 1997; Farid \& Grainger, 1996; Prunet et al., 2000; Berent, 2002; Eviatar, 1995, 1997; Schwalm et al., 2003), so it was plausible that reading direction could affect the lateralisation of colour CP. This hypothesis was tested by testing the lateralisation of blue-green colour CP in Arabic participants. The lateralisation of colour CP was investigated in experiments 1 and 2 for English and Arabic speakers-two groups of participants who differ in their reading direction. Experiment 1 used a visual search task with an RT measure whilst Experiment 2 used a target detection task with an initiation time eye-movement measure. It was found that both groups had colour CP that was stronger in the LH than the RH. This confirms the robust nature of the lateralisation of colour CP to the $\mathrm{LH}$.

\section{Implications for the Debate}

Taken together, Experiments 1 and 2 suggest that lateralised colour CP is a robust effect that is unaffected by factors such as habitual scanning direction and the requirement for a spatial decision. The LH bias in colour CP has implications for the wider debate about the origin and nature of colour categories. For example, if the LH bias is related to language it provides evidence that language contributes to colour $\mathrm{CP}$. Whilst language cannot be the origin of colour CP, as colour CP is found in pre-linguistic infants and toddlers (e.g., Franklin \& Davies, 2004), a language related LH bias suggests that at some stage after language learning, the nature of colour CP is changed.

\section{Further Research}

Now that it has been demonstrated that LH colour CP is robust, further research is needed to investigate the nature of the LH category effect, in particular the contribution of language to the LH bias. As the LH is dominant 
for most language functions, evidence for a LH bias in colour CP has been taken as evidence that language contributes to colour CP. The developmental research that suggests that the LH bias arises around the time of colour term acquisition (Franklin et al., 2008b) supports this assertion. Research using fMRI has also supported this assertion by providing evidence that language regions of the brain are more greatly activated for between-category than within-category colour discriminations (Siok et al., 2009). Now that it has been established that $\mathrm{LH}$ colour $\mathrm{CP}$ is a solid phenomenon, the next step should be to investigate how language leads to this $\mathrm{LH}$ bias.

Interestingly, Siok et al.'s fMRI investigation also found greater activation of between-than within-category colour discriminations in areas of visual cortex. This may suggest that language strengthens the colour category effect in the LH by reinforcing the perceptual distinction between different category colours at early stages of perception. There is some evidence from a recent Event-Related-Potential study, that language may affect pre-attentive stages of colour perception (Thierry, Athanasopoulos, Wiggett, Dering, \& Kuipers, 2009). That study examined an early pre-attentive ERP component (visual mis-match negativity) elicited in response to the detection of a change in colour (blue 1 - blue 2 or green 1 - green 2) for Greek and English participants. The two blues fall in different lexical categories for Greeks but not for English-speakers and Greeks showed greater visual mis-match negativity to the blue colour change than the English participants did. There were no differences between English and Greek for the green colour change where both languages use only one basic term for both greens. This study raises the possibility that language can actually influence early pre-attentive colour perception and provide strong evidence for Whorf's theory of linguistic relativity (Whorf, 1956). Further research is needed to establish whether colour language actually leads to long term perceptual change or whether colour language merely modulates perception temporarily through the activation of on-line verbal codes (Siok et al., 2009). The recent ERP and fMRI investigations also provide a useful framework for testing linguistic relativity in domains other than colour to establish how language influences perception more generally.

\section{References}

Al-rasheed, A. S. (2010). Colour Cognition in Arabic and English Speakers. Doctoral Thesis. Guildford: University of Surrey.

Beale, J. M., \& Keil, F. C. (1995). Categorical Effects in the Perception of Faces. Cognition, 57, 217-239. http://dx.doi.org/10.1016/0010-0277(95)00669-X

Berent, I. (2002). Identity Avoidance in the Hebrew Lexicon: Implications for Symbolic Accounts of Word Formation. Brian and Language, 81, 326-341. http://dx.doi.org/10.1006/brln.2001.2528

Bimler, D., \& Kirkland, J. (2001). Categorical Perception of Facial Expressions of Emotion: Evidence from Multidimensional Scaling. Cognition and Emotion, 15, 633-658. http://dx.doi.org/10.1080/02699930126214

Bornstein, M. H. (1987). Infants Are Trichromats. Journal of Experimental Child Psychology, 21, 425-445. http://dx.doi.org/10.1016/0022-0965(76)90072-2

Bornstein, M. H., Kessen, W., \& Weiskopf, S. (1976). Color Vision and Hue Categorization in Young Infants. Journal of Experimental Psychology: Human Perception and Performance, 1, 115-129. http://dx.doi.org/10.1037/0096-1523.2.1.115

Bornstein, M. H., \& Korda, N. (1984). Discrimination and Matching within and between Hues Measured by Reaction Times: Some Implications for Categorical Perception and Levels of Information Processing. Psychological Research, 46, $207-222$. http://dx.doi.org/10.1007/BF00308884

Boynton, R. M., Fargo, L., Olson, C. X., \& Smallman, H. S. (1989). Category Effect in Color Memory. Color Research and Application, 14, 229-234. http://dx.doi.org/10.1002/col.5080140505

Campanella, S., Chrysochoos, A., \& Bruyer, R. (2001). Categorical Perception of Facial Gender Information: Behavioural Evidence and the Face-Speech Metaphor. Visual cognition, 8, 237-262.

http://dx.doi.org/10.1080/13506280042000072

Campbell, R., Woll, B., Benson, P., \& Wallaca, S. B. (1999). Categorical Perception of Face Actions: Their Role in Sign Language in Communicative Facial Displays. Quarterly Journal of Experimental Psychology, 52, 67-95. http://dx.doi.org/10.1080/713755802

Cutting, J. E., \& Rosner, B. S. (1974). Categories and Boundaries in Speech and Music. Perception and Psychophysics, 16, 564-570. http://dx.doi.org/10.3758/BF03198588

Daoutis, C. A., Franklin, A., Riddet, A., Clifford, A., \& Davies, I. R. L. (2006a). Categorical Effects in Children’s Colour 
Search: A Cross-Linguistic Comparison. British Journal of Developmental Psychology, 24, 373-400. http://dx.doi.org/10.1348/026151005X51266

Daoutis, C. A., Pilling, M., \& Davies, I. R. L. (2006b). Categorical Effects in Visual Search of Colour. Visual Cognition, 14, 229-234. http://dx.doi.org/10.1080/13506280500158670

De Gelder, B. L. M. F., Teunisse, J. P., \& Benson, P. J. (1997). Categorical Effects of Facial Expressions: Categorical and Their Internal Structure. Cognition and Emotion, 11, 1-23. http://dx.doi.org/10.1080/026999397380005

Drivonikou, G. V., Davies, I. R. L. Franklin, A., \& Taylor, C. (2007b). Lateralisation of Colour Categorical Perception: A Cross-Cultural Study. Perception, 36, ECVP Abstract Supplement.

Drivonikou, G. V., Kay, T., Regier, R. B., Ivry, A. L., Franklin, A., \& Davies, I. R. L. (2007a). Further Evidence That Whorfian Effects Are Stronger in the Right Visual Field than the Left. Proceeding of the National Academy of Sciences, 104, 1097-1102. http://dx.doi.org/10.1073/pnas.0610132104

Etcoff, N. L., \& Magee, J. J. (1992). Categorical Effects in the Perception of Faces. Cognition, 57, 217-239.

Eviatar, Z. (1995). Reading Direction and Attention: Effects on Lateralized Ignoring. Brian and Cognition, 29, 137-150. http://dx.doi.org/10.1006/brcg.1995.1273

Eviatar, Z. (1997). Language Experience and Right Hemisphere Task: The Effects of Scanning Habits and Multilingualism. Brian and Cognition, 58, 157-173.

Farid, M., \& Grainger, J. (1996). How Initial Fixation Position Influences Visual Word Recognition: A Comparison of French and Arabic. Brian and Language, 53, 351-368. http://dx.doi.org/10.1006/brln.1996.0053

Fletcher, R. (1980). The City University Colour Vision Test. Windsor, Berks: Keeler Ltd.

Franklin, A., \& Davies, I. R. L. (2004). New Evidence for Infant Colour Categories. British Journal of Developmental Psychology, 22, 349-377. http://dx.doi.org/10.1348/0261510041552738

Franklin, A., Drivonikou, G. V., Bevis,, L., Davies, I. R. L., Kay, P., \& Regier, T. (2008a). Categorical Perception of Color Is Lateralised to the Right Hemisphere in Infants, But to the Left Hemisphere in Adults. Proceedings of the National Academy of Sciences, 105, 3221-3225. http://dx.doi.org/10.1073/pnas.0712286105

Franklin, A., Drivonikou, G. V., Clifford, A., Kay, P., Regier, T., \& Davies, I. R. L. (2008b). Laterlization of Categorical Perception of Color Changes with Color Term Acquisition. Proceedings of the National Academy of Sciences, 47, 1822118225. http://dx.doi.org/10.1073/pnas.0809952105

Franklin, A., Pilling, M., \& Davies, I. R. L. (2005). The Nature Color Categorisation: Evidence from Eye-Movements on a Target Detection Task. Journal of Experimental Child Psychology, 91, 227-248. http://dx.doi.org/10.1016/j.jecp.2005.03.003

Fujisaki, H., \& Kawashima, T. (1971). On the Modes and Hearing Mechanisms of Speech Perception. Annual Report of the Engineering Research Institute, 28, Tokyo: Faculty of Engineering. University of Tokyo.

Gilbert, A. L., Regier, T., Kay, P., \& Ivry, R. B. (2006). Whorfian Hypothesis Supported in the Right Visual Field But Not the Left. Proceeding of the National Academy of Sciences, 103, 489-494. http://dx.doi.org/10.1073/pnas.0509868103

Gilbert, A. L., Regier, T., Kay, P., \& Ivry, R. B. (2007). Supported for Lateralization of the Whorf Effect beyond the Realm of Color Discrimination. Brian and Language.

Goldstone, R. L., Lippa, Y., \& Shiffrin, R. M. (2001). Altering Object Representations through Category Learning. Cognition, 78, 27-43. http://dx.doi.org/10.1016/S0010-0277(00)00099-8

Han, S., \& Northoff, G. (2008). Culture-Sensitive Neural Substrates of Human Cognition: A Transcultural Neuroimaging Approach. Nature Reviews Neuroscience, 9, 646-654. http://dx.doi.org/10.1038/nrn2456

Harnad, S. (1987). Categorical Perception: The Groundwork of Cognition. New York: Cambridge University Press.

Harnad, S., Hanson, S. J., \& Lubin, J. (1991). Categorical Perception and the Evolution of Supervised Learning in Neural Nets. In D. W. Powers, \& L., Reeker (Eds), Working Papers of the AAAI Spring Symposium on Machine Learning of Natural Language and Ontology, 65-74. Presented at Symposium on Symbol Grounding: Problems and Practice, Stanford University, March 1991.

Ishihara, S. M. (1987). Ishihara's Tests for Colour-Blindness. Tokyo: Kanehara \& Co.

Jager, G., \& Postma, A. (2003). On the Hemispheric Specialization for Categorical and Coordinate Spatial Relations: A Review of the Current Evidence. Neuropsychologia, 41, 504-515. http://dx.doi.org/10.1016/S0028-3932(02)00086-6

Kay, P., \& Kempton, W. (1984). What Is the Sapir-Whorf Hypothesis? American Anthropologist, 86, 65-79. http://dx.doi.org/10.1525/aa.1984.86.1.02a00050

Kazandjian, S., \& Chokron, S. (2008). Paying Attention to Reading Direction. Nature Reviews: Neuroscience. http://dx.doi.org/10.1038/nrn2456-c1

Kosslyn, S. M., Koenig, O., Barrett, A., Cave, C. B., Tang, J., \& Gabrieli, J. D. E. (1989). Evidence for Two Types of Spatial 
Representations: Hemispheric Specialization for Categorical and Coordinate Relations. Journal of Experimental Psychology: Human Perception and Performance, 15, 723-735. http://dx.doi.org/10.1037/0096-1523.15.4.723

Laws, G., Davies, I., \& Andrews, C. (1995). Linguistic Structure and Non-Linguistic Cognition: English and Russian Blues Compared. Language and Cognitive Processes, 10, 59-94. http://dx.doi.org/10.1080/01690969508407088

Levin, D. T., \& Angelone, B. L. (2002). Categorical Perception of Race. Perception, 31, 567-578. http://dx.doi.org/10.1068/p3315

Liberman, A. M., Harris, K. S., Hoffman, H. S., \& Griffith, B. C. (1957). The Discrimination of Speech Sounds within and across Phoneme Boundaries. Journal of Experimental Psychology, 45, 358-368. http://dx.doi.org/10.1037/h0044417

Liu, Q., Li, H., Campos, J. L., Wang, Q., Zhang, Y., Qiu, J., Zhang, Q., \& Sun, H. (2009). The N2pc Component in ERP and Lateralization Effect of Language on Color Perception. Neuroscience Letters, 454, 58-61.

http://dx.doi.org/10.1016/j.neulet.2009.02.045

Özgen, E., \& Davies, I. R. (2002). Acquisition of Categorical Color Perception: A Perceptual Learning Approach to the Linguistic Relativity Hypothesis. Journal of Experimental Psychology, 131, 477-493. http://dx.doi.org/10.1037/0096-3445.131.4.477

Pastore, R. E., Li, X., \& Layer, J. K. (1990). Categorical Perception of Non-Speech Chirps and Bleats. Perception and Psychophysics, 48, 151-156. http://dx.doi.org/10.3758/BF03207082

Pilling, M., Wiggett, A., Özgen, E., \& Davies, I. R. L. (2003). Is Color “Categorical Perception” Really Perceptual? Memory and Cognition, 31, 538-551. http://dx.doi.org/10.3758/BF03207082

Prunet, J. F., Beland, R., \& Idrissi, A. (2000). The Mental Representation of Semitic Word. Linguistic Inquiry, 31, 609-648. http://dx.doi.org/10.1162/002438900554497

Roberson, D., \& Davidoff, J. (2000). The Categorical Perception of Colors and Facial Expressions: The Effect of Verbal Interference. Memory and Cognition, 28, 977-986. http://dx.doi.org/10.3758/BF03209345

Roberson, D., Davidoff, J., \& Braisby, N. (1999). Similarity and Categorisation: Neuropsychological Evidence for a Dissociation in Explicit Tasks. Cognition, 71, 1-42. http://dx.doi.org/10.1016/S0010-0277(99)00013-X

Roberson, D., Davies, I. R. L., \& Davidoff, J. (2000). Color Categories Are Not Universal: Replications and New Evidence from a Stone-Age Culture. Journal of Experimental Psychology: General, 129, 369-398. http://dx.doi.org/10.1037/0096-3445.129.3.369

Roberson, D., Park, H., \& Hanley, R. J. (2008). Categorical Perception of Colour in the Left and Right Visual Field Is Verbally Mediated: Evidence from Korean. Cognition, 107, 752-762. http://dx.doi.org/10.1016/j.cognition.2007.09.001

Rossion, B., Schilitz, C., Laurence, R., Pirenne, D., \& Grommelinck, M. (2001). How Does the Brain Discriminate Familiar and Unfamiliar Faces? A PET Study of Face Categorical Perception. Journal of Cognitive Neuroscience, 13, 1019-1034.

Sandell, J. H., Gross, C. C., \& Bornstein, M. H. (1979). Color Categories in Macaques. Journal of Comparative and Physiological Psychology, 93, 626-625. http://dx.doi.org/10.1037/h0077594

Schwalm, N. D., Eviatar, Z., Golan, Y., \& Blumenfeld, Y. (2003). The Effect of Reading Direction Habit on Numerical Processing. Proceeding of the Human Factors and Ergonomics Society, 47th, Annual Meeting, 1649-1653. http://dx.doi.org/10.1177/154193120304701312

Simola, J., Holmqvist, K., \& Lindgren, M. (2009). Right Visual Field Advantage in Parafoveal Processing: Evidence from Eye-Fixation-Related Potentials. Brain and Language, 111, 101-113. http://dx.doi.org/10.1016/j.bandl.2009.08.004

Siok, W. T., Kay, P., Wang, W. S. Y., Chan, A. H. D., Chen, L., Luke, K., \& Tan, L. H. (2009). Language Regions of Brain Are Operative in Color Perception. Journal of Experimental Psychology: Human Perception and Performance, 106, 81408145.

Tajfel, H., \& Wilkes, H. (1963). Classification and Quantitative Judgment. British Journal of Psychology, 54, 101-114. http://dx.doi.org/10.1111/j.2044-8295.1963.tb00865.x

Tan, L. H., Chan, A. H. D., Kay, P., Khong, P., Yip, L. K. C., \& Luke, K. (2008). Language Affects Patterns of Brain Activation Associated with Perceptual Decision. Journal of Experimental Psychology: Human Perception and Performance, 105, 4004-4009.

Thierry, G., Athanasopoulos, P., Wiggett, A., Dering, B., \& Kuipers, J. R. (2009). Unconscious Effects of LanguageSpecific Terminology on Pre-Attentive Color Perception. Proceedings of the National Academy of Sciences, 106, 45674570. http://dx.doi.org/10.1073/pnas.0811155106

Uchikawa, K., \& Shonida, H. (1996). Influence of Basic Color Categories on Color Memory Discrimination. Color Research and Application, 21, 430-439. http://dx.doi.org/10.1002/(SICI)1520-6378(199612)21:6<430::AID-COL5>3.0.CO;2-X

Winawer, J., Witthoft, N., Frank, M., Wu, L., Wade, A., \& Boroditsky, L. (2007). Russian Blues Reveal Effects of Language on Color Discrimination. Proceedings of the National Academy of Sciences, 104, 7780-7785. 
A. Al-Rasheed et al.

http://dx.doi.org/10.1073/pnas.0701644104

Whorf, B. L. (1956). Language Thought and Reality. Cambridge MA: MIT Press. 